\title{
NEW ANALYSIS AND DIAGNOSTIC TOOLS FOR IMPROVING GOVERNANCE IN URBAN PLANNING AND LAND MANAGEMENT
}

\author{
S. GARCÍA-AYLLÓN ${ }^{1} \&$ G. MARTÍNEZ MARÍ ${ }^{2}$ \\ ${ }^{1}$ Technical University of Cartagena (UPCT), Spain. \\ ${ }^{2}$ The Region of Murcia's General Office for Land and Housing, Spain.
}

\begin{abstract}
The Spanish Region of Murcia was one of the several European regions, departments and provinces located in the Mediterranean area to participate in a number of ERDF-funded European research projects, which took place from 2008 to 2013. The aim of those projects was to create both methodologies and tools for improving governance in urban and regional planning. Issues such as land consumption, changes in land use or regional specialization policies as designed by government authorities are essential for achieving a balanced development in regions and cities. The said research projects have resulted in the creation of new analysis and diagnostic methodologies for improving political governance in the fields of land management and land use planning, as well as for achieving a more sustainable development in the cities involved. This paper presents the results of one of the research projects above - namely OSDDT - by means of land use indicators and urban operational tools. It is held that integrating research findings into the current relevant legislation will allow for generating new methods for studying urban and regional planning.

Keywords: GIS tools, land management, land use indicators, urban operational tools, urban planning.
\end{abstract}

\section{THE OSDDT PROJECT: LAND CONSUMPTION AS A VARIABLE FOR PREDICTING FUTURE TRENDS IN LAND USE.}

In recent years, the Spanish Region of Murcia has participated in a series of land use research projects such as Naturba (2009-2012), Pays-Med-Urban (2009-2011), OSDDT (2009-2013) and Otremed (2010-2013). These research projects have been funded by the European Regional Development Fund (referred to as ERDF, heretofore) through the MED [1] and SUDOE Interreg IV [2] EU programs. Two of those projects are particularly interesting for land governance, namely OSDDT (Occupation des Sols et Développement Durable du Territoire sur l'arc méditerranéen, French for 'Land Use and Sustainable Development of Territories in the Mediterranean Area') and Otremed (Observatorio Territorial en Red del Mediterráneo, Spanish for 'Web-based Land Observatory for the Mediterranean Area').

Land consumption is inherent to urban growth, which is in its turn a pre-eminent issue in contemporary societies. The use of land for housing, infrastructure and other activities has increased to such an extent for the last thirty years that the beneficial properties of agricultural land are being compromised and our rich biodiversity is endangered as well [3] (Fig. 1).

These changes in land use may have a serious impact on ecosystems by disturbing them or even threatening their existence. That being so, the OSDDT project has allowed for measuring land consumption and developing methods for the identification of operational tools which may, on the one hand, specifically reduce the impact of land consumption on ecosystems and, on the other hand, help the project's partners with developing awareness-raising consultation practices on this issue. As for the Otremed project, it has allowed for creating a geoportal, which is able to perform fast web-based diagnoses of land use by using the indicators and methodologies developed for the OSDDT project.

One of the goals of both the OSDDT and the Otremed projects was sharing prospective results with policy-makers, local government authorities, experts, lay citizens and associations involved in 


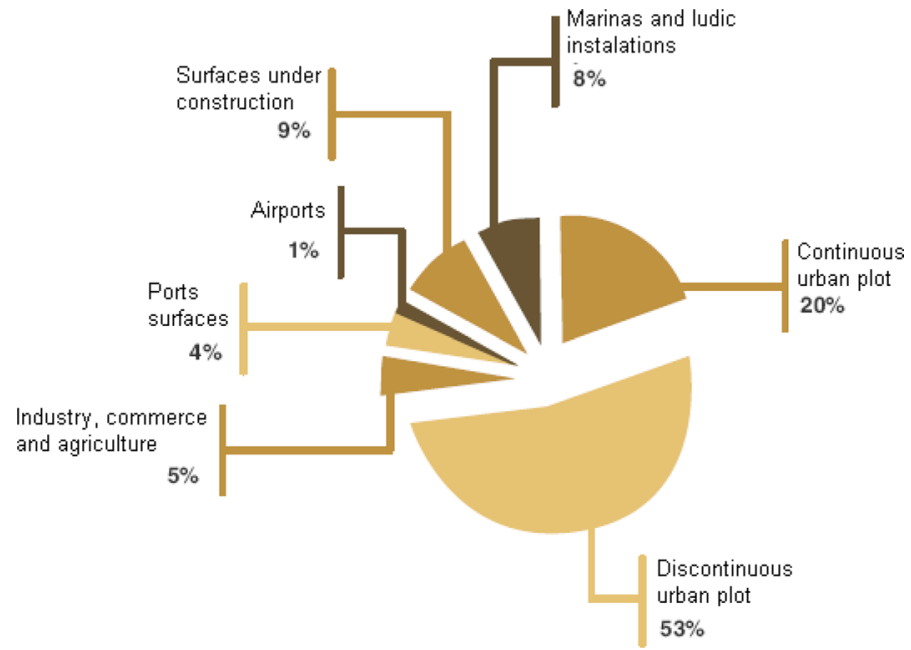

Figure 1: Example of land use in transformed areas on the Spanish coastal strip. Source: [4].

the preservation of natural resources. The OSDDT project established three different research areas for achieving that goal. They were, respectively, concerned with creating:

- Indicators for measuring land consumption.

- Operational tools for land management so as to reduce land consumption.

- Consultation and communication tools for raising awareness on issues related to land development and conservation.

This paper will address the first two areas, while keeping the third - related to some of the results yielded by the Otremed Project - for a prospective paper..

\section{INDICATORS FOR MEASURING LAND CONSUMPTION}

Land consumption indicators provide basic data for establishing comparisons between different areas. All of the OSDDT project's partners relied on basic geographic data that could be delivered irrespective of local restraints and the respective countries' relevant legislation. This implies that parameters may apply to a substantial part of the areas concerned - at provincial and regional levels, at least - regardless of local conditions and peculiarities. Bearing this in mind, it seems very likely that the awareness of local authorities may thus be raised so as to use the said indicators in their own areas of jurisdiction in order to assess the conditions for achieving more restrained land consumption levels.

Indicators must assess the current situation as well as changes in land consumption, thus providing information on past dynamics and present trends (Figs 2 and 3). They are essential instruments for those in charge of land use planning insofar as they may help the latter with adopting specific development criteria for land preservation; they may also yield the best possible results in the process for reducing excessive land consumption.

Both European - e. g. the INSPIRE directive [5] - and member state-level legislation emphasize the need for the kind of indicators presented in this paper to be useful in assessing land consumption levels and rendering geographic information on the areas concerned accessible to the public. 


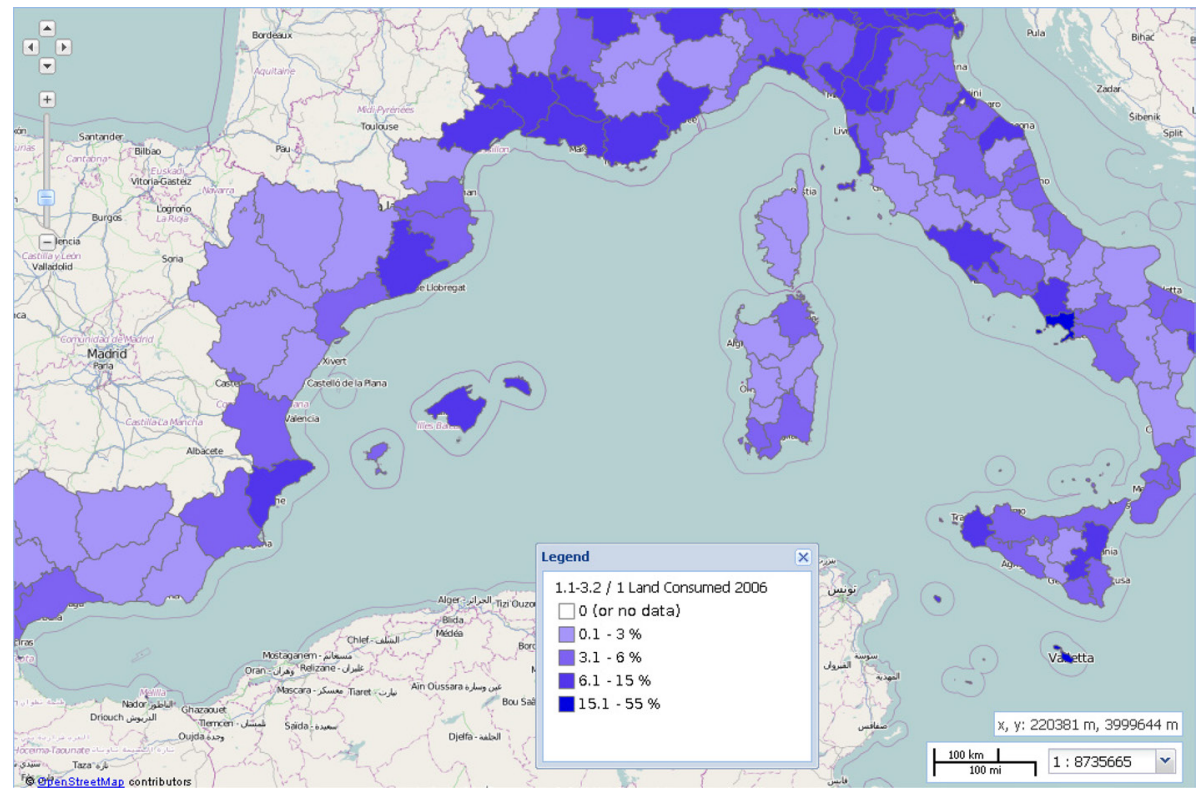

Figure 2: Land consumption in Euro-Mediterranean areas until 2006. Source: [4].

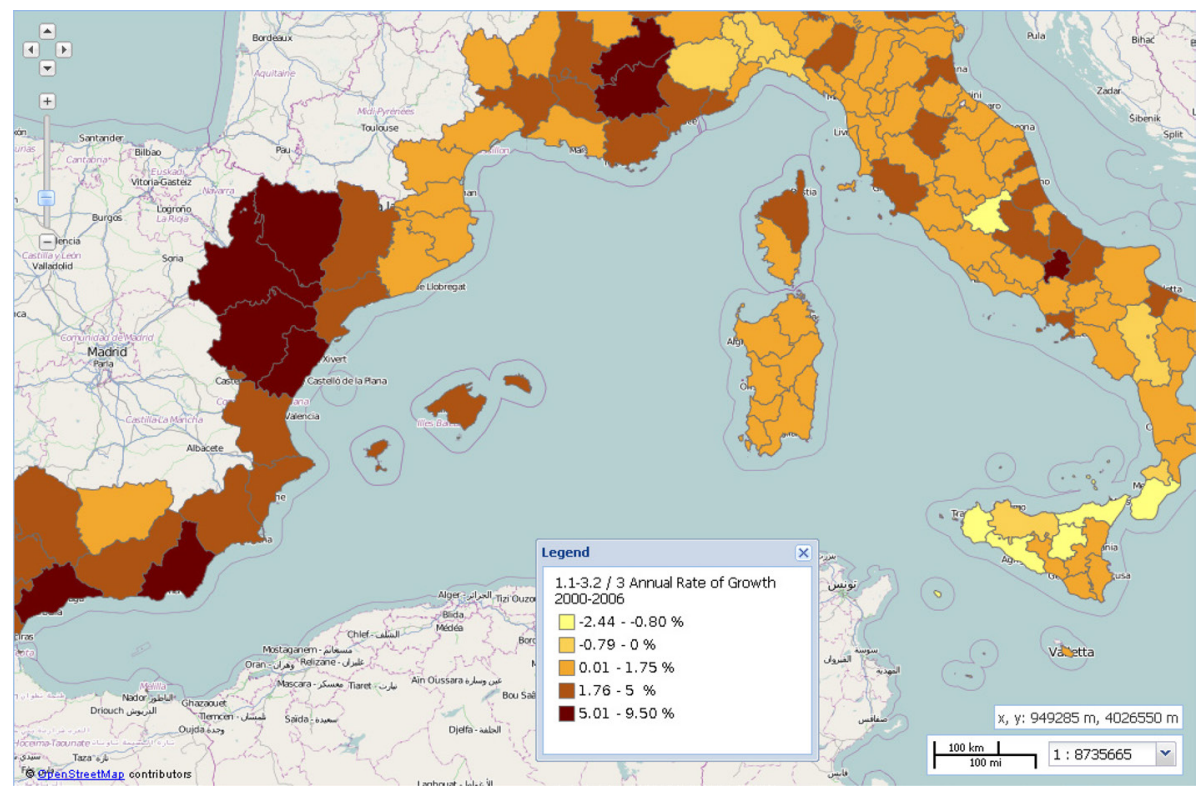

Figure 3: Annual growth rate (2000-2006). Source: [4]. 
Organizing research may decisively contribute to foster quality scientific production as well as to improve public knowledge of this issue.

A good land consumption indicator is by definition built on data treatment methods based on the identification of artificialized and natural areas, rather than on methods having recourse to land registers or available satellite images - such as 'geolocation cartography' - that may be used with GIS tools. The reliability of data treatment methods determines the quality of evolution assessment specifically as far as urban spreading is concerned.

Choosing the appropriate indicators to create a system for the monitoring and evaluating land consumption and urban spreading processes is therefore a complex matter. For the monitoring system to work, the adoption of a number of criteria is required, particularly when a partnership between territorial agents with different interests exists. Relevant interests must be then integrated in order to develop reliable indicators, and skills for analysing results in terms of assets and limitations must be used.

It is essential that the indicator definitions remain constant from one reading to another as far as the parameters used are concerned, so that temporal deviations are as close to reality as possible. Indicators must provide understandable information as well as being accepted by all parties involved in order to be shared and made available to the public: this was the case with the OSDDT project. As for the agents involved in the process and local government authorities' decisions - especially at sub-municipal level - it is sometimes necessary to have more detailed indicators for higher accuracy (Fig. 4).

Quantitative results have the advantage of allowing for quick comparison on the part of decision makers. Similarly, they often appear to be more accurate and even reflect hard facts. For a more

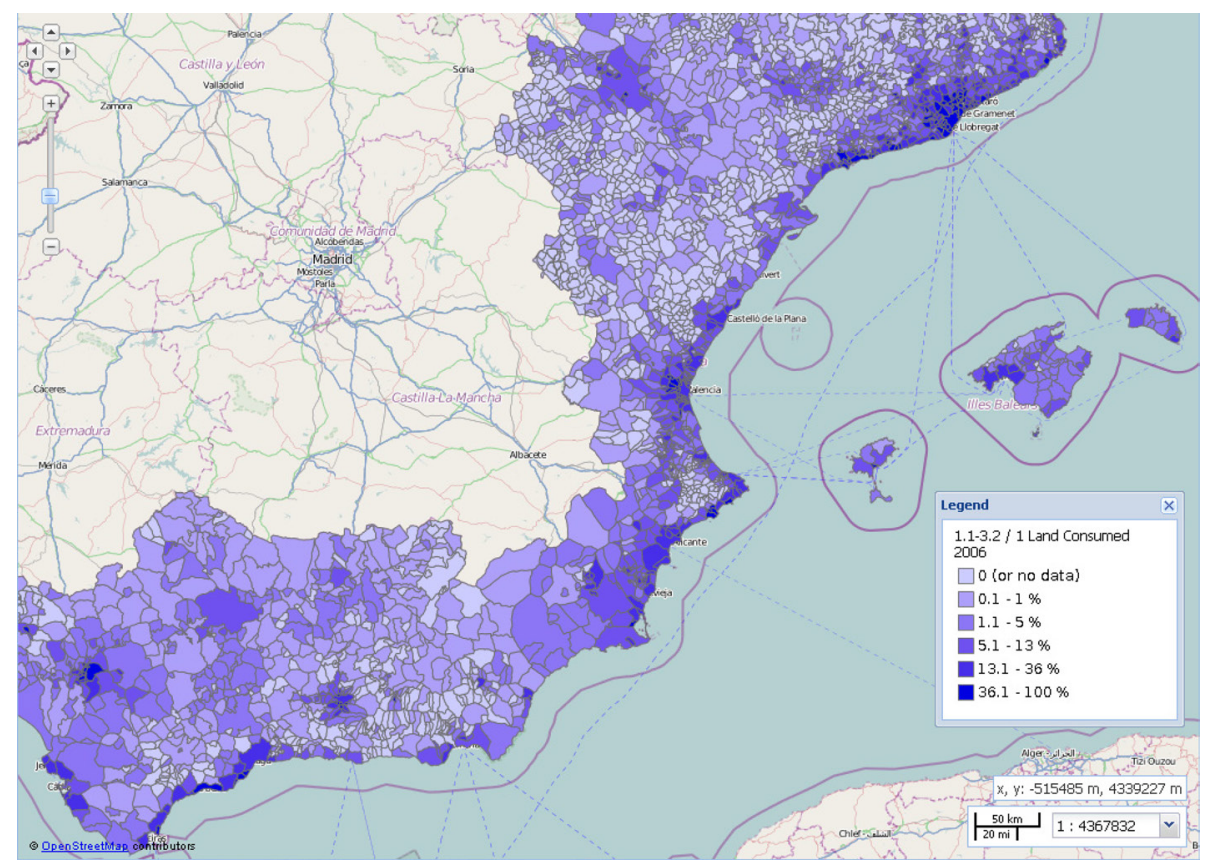

Figure 4: Land consumption on the Spanish Mediterranean coastal strip by local government authorities until 2006. Source: Sdimed. 
comprehensive understanding of issues, though, it is given that qualitative analysis permits to broaden the dynamics shown by the measures carried out, as well as modifying the different points of view held by the 'agents' involved in land consumption.

In some cases, qualitative data did prove to be necessary in order to understand and analyze a given measurement; in some others, calculations pointing to the existence of a given dynamic were not necessarily as clarifying. Irrespective of land, structural, local and regional specifications, it is essential that the battery indicators made available to the observer are the same for all operators and experts involved in the observation and monitoring of land consumption, so that useful information and knowledge may be obtained about the issues concerned at a European level. The validity of the indicators developed as a part of the OSDDT project was proved later on when they were confronted with the operational tools used to reduce land consumption.

Indicators are required for assessing land consumption as well as for defining and applying models for a more restrained territorial planning as far as property management is concerned. A thorough knowledge of both the origin of urban spreading and that of agricultural land regression is essential. Similarly, predictions can be made by using the new indicators' definition - through an assessment of the application of operational tools and that of planning models for low-intensity land use. This would allow for an assessment of the indicators' actual effectiveness and an understanding of their different components. In case of negative results, it would then be possible to immediately make all the necessary corrections and adjustments.

A second stage of the process begins after putting the tools or operational management models to use; the indicators then become essential instruments to determine the efficacy of the aforesaid tools in the fight against land consumption. If the indicators show that the tools used are effective, this has to be transmitted to decision makers and local government authorities responsible for validating the tools' suitability as well as for supporting their promotion and use. It is important to remind that GIS tools have a dual role as far as indicators are concerned: they are both tools for spatial analysis and/ or instruments for the showing of the results, which will be used by decision makers and other target groups.

Conversely, if the results derived from putting to use both the indicators and the operational tools fail to meet the previously set objectives, the tools will have to be accordingly modified and rearranged, then once again be tested by undergoing a new evaluation cycle for the purposes of checking their efficacy. Operational tools should ideally undergo as high a number of evaluation cycles as possible, until they meet the initial requirements (Fig. 5). Evaluation cycles include indicators' calculation.

As a part of the OSDDT project, the Region of Murcia's authorities acknowledged from the very beginning that an array of indicators that was applicable to different European contexts and shared by all of them was required. Indicators were identified and designed as per the principles mentioned above, which resulted in the creation of three different groups of indicators. The aim was twofold: first, to have some instruments for interpretation which where as thorough as possible; second, to move away from simple quantitative measurements of land consumption to the assessment of operational tools' efficacy in reducing land consumption - this being the ultimate goal.

\subsection{First group of indicators: land consumption rate within study areas}

The first group of indicators must supply accurate quantitative readings of land consumption within the study areas. This choice was based on the need for providing all of the local agents with the ability to measure land consumption. A turning point was indeed reached by the end of the last decade when it was realized that such a thing as a 'land consumption problem' did actually exist but this 


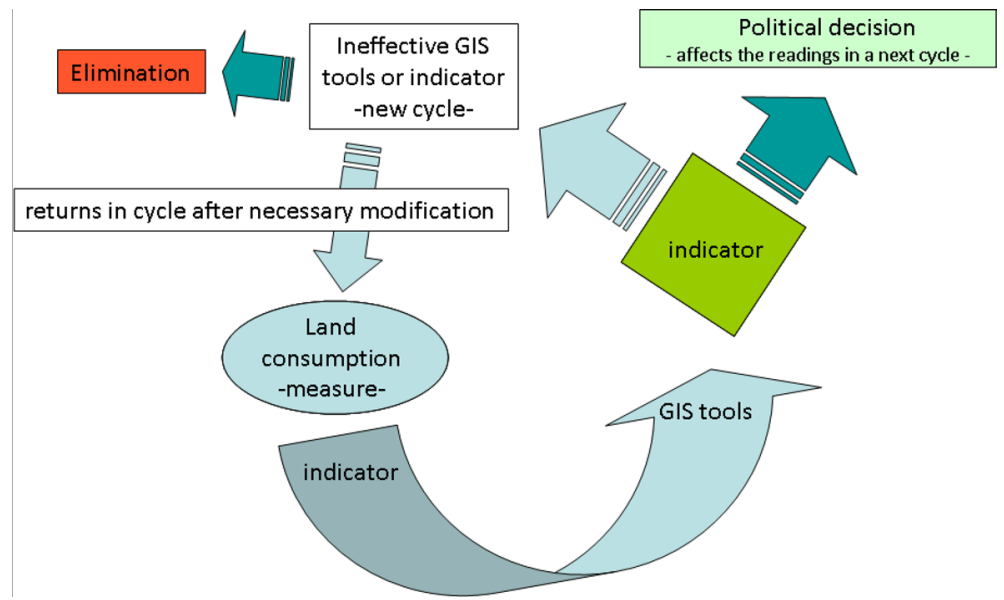

Figure 5: Ideal evaluation cycle for operational tools.

realization was only rarely supported by quantitative measurements at the local level. Therefore, it was deemed necessary to devise a series of instruments, which might allow for the gathering of knowledge on a shared basis - that knowledge effectively leading to an understanding of land consumption.

The design of the first group of indicators was, therefore, underscored by one of the aims of the OSDDT project: to gather a minimum body of knowledge on land consumption in order to be able to conduct research activities on the essential aspects of land protection - such as preserving natural areas as well as those clearly destined for agricultural use. It is necessary that local-level data - e. g. cartography, land registry, photographic records, etc. - are available for the design of indicators whose definition may include the state of the study areas and the evolution of land consumption.

These are the first group's main indicators:

\section{Indicator 1: Percentage of used land within the study area.}

Calculation method: extent of urbanized/artificial land up to a given date/as brought to the knowledge of province, department or local council authorities. Expressed as a percentage.

$$
\text { Formula: } \mathrm{C}=\mathrm{S}_{\mathrm{U}} / \mathrm{S}
$$

where $\mathrm{C}$ is the used land, $\mathrm{S}_{\mathrm{U}}$ the urbanized or artificial land area (buildings plus sport grounds, quarries and docks) and $S$ the study area.

\section{Indicator 2: Intensity of land use}

Calculation method: urban land use within a given period of time between two dates in the year subject to survey. Expressed in percentages.

This calculation requires that land use be measured at two different dates.

$$
\text { Formula: } \mathrm{I}=100-\left(\mathrm{C}_{2} * 100 / \mathrm{C}_{1}\right)
$$

where $\mathrm{I}$ is the land consumption intensity, $\mathrm{C}_{1}$ the area subject to land consumption [date 1], and $\mathrm{C}_{2}$ the area subject to land consumption [date 2]. 
Indicator 3: Average annual land consumption increase rate.

Calculation method: annual land consumption rate is expressed as land consumption percentage over a specific period. This calculation requires that land use be measured at two different dates for the annual variation to be calculated.

$$
\text { Formula: } \mathrm{T}_{\mathrm{i}}=100 *\left[\left(\mathrm{C}_{2}-\mathrm{C}_{1}\right) /\left(\mathrm{a} * \mathrm{C}_{1}\right)\right]
$$

where $\mathrm{T}_{\mathrm{i}}$ is the average growth rate, $\mathrm{C}_{2}$ the land consumption value/measurement on date $2, \mathrm{C}_{1}$ the land consumption value/measurement on date 1 and a the difference between the two measurements (expressed in number of years).

Indicator 4: Fertile soil consumption.

Calculation method: Fertile soil is subject to land consumption over a given period of time in relation to total existing fertile soil area at regional and/or local levels. Final data are expressed as a percentage.

$$
\text { Formula: } \mathrm{C}_{\mathrm{sf}}=\mathrm{SU}_{\mathrm{sf}} / \mathrm{S}
$$

where $\mathrm{C}_{\mathrm{sf}}$ is the fertile soil subject to land consumption, $\mathrm{SU}_{\mathrm{sf}}$ the urbanized/artificial fertile soil (buildings plus parking, roads, etc.) and $\mathrm{S}$ the total fertile soil area.

This indicator makes it possible to take into consideration all of the different definitions of fertile soil according to the national legislations of the OSDDT project partners. Comparing the available relative data on areas subject to land consumption with those concerning fertile soil consumption is necessary for identifying the total extent of fertile soil subject to land consumption. The intersection between both sets of data typically represents the extent of fertile soil subject to land consumption.

\section{Indicator 5: Land consumption in relation to altitude (expressed as a percentage).}

Calculation method: land consumption by altitude is expressed as a percentage as well as in height. Metric units of measurement have fixed 100-m intervals, e.g. 0-100 m, 100-200 m, 200-300 m, etc.

$$
\text { Formula: } \mathrm{F}_{\mathrm{x}}=\Sigma \mathrm{C}_{\mathrm{S}} \text { in } \mathrm{F}_{\mathrm{x}}
$$

where $\mathrm{F}_{\mathrm{x}}$ is the altitude corresponding to a particular area and $\mathrm{C}_{\mathrm{S}}$ in $\mathrm{F}_{\mathrm{x}}$ the land consumption in the said area.

Merging the data for land consumption with those for altitude is necessary for identifying the extent of land subject to consumption. The sum total of both values stands for land consumption as a function of metric altitude.

\section{Indicator 6: Land consumption in relation to population.}

Calculation method: the relationship between the extent of the area subject to land consumption and the population living on the said area as expressed in $\mathrm{km}^{2} /$ inhabitant or in ha/inhabitant. It is essential that the relative data on the areas subject to land consumption correspond to the same date - or that this date is the nearest possible one - in which the data on the study area's population were gathered. For example, if the data for land consumption were gathered in 2006, the data for population in the study area will likewise have to reflect the situation in 2006.

$$
\text { Formula: } \mathrm{C}_{\mathrm{ab}}=\mathrm{C}_{\mathrm{S}} / \mathrm{hab}
$$

where $\mathrm{C}_{\mathrm{ab}}$ is the area subject to land consumption in relation to inhabitants, $\mathrm{C}_{\mathrm{S}}$ the area subject to land consumption $\left(\mathrm{km}^{2}\right.$, ha) and hab the number of inhabitants 
Indicator 6b: Area subject to land consumption expressed in square metres in relation to additional inhabitants in a given area between two dates.

Calculation method: the relationship between the increase in the extent of the area subject to land consumption and the demographic population in that area.

$$
\text { Formula: } \mathrm{C}_{\mathrm{SAbS}}=\left(\mathrm{C}_{\mathrm{S} 2}-\mathrm{C}_{\mathrm{S} 1}\right) /\left(\mathrm{hab}_{2}-\mathrm{hab}_{1}\right)
$$

where $\mathrm{C}_{\mathrm{SAbS}}$ is the area subject to land consumption in relation to additional inhabitants, $\mathrm{C}_{\mathrm{S} 1}$ the area subject to land consumption in period $1, \mathrm{C}_{\mathrm{S} 2}$ the area subject to land consumption in period $2, \mathrm{hab}_{1}$ the number of inhabitants in period 1 and hab $_{2}$ the number of inhabitants in period 2.

\section{Indicator 7: Environmental protection (expressed as a percentage).}

Calculation method: area subject to land consumption (expressed in $\mathrm{m}^{2}$ ) and protected areas under the relevant legislation in the study area.

This indicator shows the extent of land subject to land consumption within protected areas - e.g. natural parks, EU-Natura 2000 protected areas, SIC, etc. - in the study area. The said extend of land is expressed as a percentage.

$$
\text { Formula: } \mathrm{I}_{\mathrm{pa}}=\mathrm{C}_{\mathrm{sa}} / \mathrm{S} * 100
$$

where $\mathrm{C}_{\mathrm{sa}}$ is the area subject to land consumption in protected areas created under the relevant environmental protection legislation and $\mathrm{S}$ the study area.

\section{Indicator 8: Tourism-related pressure on land use.}

Calculation method: a relationship between tourist population and local resident population. Maximum tourist population is reached when all available beds in the study area's hotels have been occupied.

This rate reflects the multiple factors associated with tourist population. For comparison purposes, detailed data on the number of available rooms in the study area's hotels and the number of campers in the study area's camping sites must be 'converted' into number of beds or an equivalent to number of persons - e.g. a camping site will be understood to include a number of camping areas allowing for three campers each; hotel rooms will allow two people in; and secondary residences will be understood to include five persons each.,

$$
\text { Formula: } \mathrm{p}_{\mathrm{t}}=\operatorname{pop}_{\mathrm{T}} * / \mathrm{hab}
$$

where $\mathrm{P}_{\mathrm{t}}$ is the tourism-related pressure on land use, pop $_{\mathrm{T}}$ the maximum population (theoretical) and hab the local resident population.

A number of the indicators included in the first group go beyond mere gathering of quantitative data on land consumption between two given dates; they also allow for a reading of land consumption's dynamics through an analysis - a quantitative one, to be sure - that may yield more accurate measurements as far as land specifics are concerned. The indicators take into consideration the public's major concerns in relation to land consumption, namely the following:

1. The public and other relevant agents' increasing attention to the dangers related to the constant shrinkage of land - as areas traditionally used for agricultural purposes are very often bought and sold as a part of residential and industrial operations nowadays.

2. The risks posed by ill-conceived land management policies and the latter's link with the increase in accidents and 'natural' disasters - e.g. rock slide, flooding, violent thunderstorms, etc. - in urban areas. 
The first group of indicators thus affords a series of different measuring instruments permitting to determine the ways in which land consumption may have had an impact on vulnerable areas - e.g. determining when and how those areas' original use has been altered. The first group of indicators also allows for local government authorities to tackle land consumption in their respective areas of jurisdiction as well as to intervene in the allocation of local non-renewable legacy resources such as agriculture, landscape, hydrograph and biodiversity.

\subsection{Second family of indicators: urban sprawl indicators}

The use of the indicators included in the first group did show that all the study areas in the OSDDT project had something in common: land consumption in those areas during the last decades was partially attributable to a kind of 'disorderly' urban growth outside of urban centres and agglomerations, located mainly in rural areas as well as on the coastal strip.

Usually described as 'urban sprawl', this type of urban growth may have an occasionally strong impact on both land and the environment and is not constrained by land planning. The urbanization process represented by urban sprawl is an irregular one but poses a number of prospective risks - if only for the fact that it might lead the agents involved to question the agricultural orientation of the areas undergoing urban sprawl. That is why those agents must learn how to design the appropriate indicators for understanding urban sprawl. This second group of indicators aims precisely at that goal.

Defining urban sprawl is the first necessary step towards implementing calculation modalities that are a function of the facts in the field. The OSDDT project partners may not use the same definition for urban sprawl, but the creation of new urban cores in sparsely urbanized areas has the same implications for all of them - namely, the fact that construction activities in these agricultural or natural areas have an invasive character. Those activities could also represent a start for continuing trends leading to urbanization in distinct rural areas located within urban aggregated towns, villages and peripheral-urban areas. The creation of new urban cores in sparsely urbanized areas is considered to be the beginning of future urban growth.

Using urban sprawl indicators for analysis purposes and integrating them into land planning systems may allow for protecting all those areas whose preservation should be a priority. Using the indicators as well as measuring urban sprawl on a continuing basis may indeed make it possible to understand the dynamics of agricultural production in areas located around urban agglomerations and therefore reform planning instruments. The main goal is introducing preservation measures aimed at natural and agricultural areas so that their potential for development as well as the European nations' food sovereignty is maintained - also by having recourse to vegetable and animal production from peripheral-urban areas.

Now these are the indicators included in the second group:

\section{Indicator 9: Urban dispersion indicator.}

Calculation method: area subject to land consumption in non-urbanized districts

$$
\text { Formula: Sprawl }=\mathrm{C}_{\mathrm{sl}}
$$

where $\mathrm{C}_{\mathrm{sl}}$ is the area subject to land consumption in non-urbanized districts $(\mathrm{Ha})$.

According to the Italian province of Turin's PTC [6], non-urbanized districts are those essentially agricultural or natural areas with a markedly sparse urban density. Urban density in non-urbanized areas may be calculated through GIS modelling and will be defined and discussed in a prospective 
paper. The methodology associated with this indicator is for informative purposes and users are not required to have recourse to it; however, they are expected to use other calculation methods whose validity has been properly asserted.

\section{Indicator 10: Sprawl/mix incidence.}

Calculation method: the total area for new urban cores located within non-urbanized districts - i.e. consolidated or dense 'Outside Development Zones' (ODZ), as well as transitional areas connected to $\mathrm{ODZ}$ - in relation to total area for consolidated urban districts in a given period.

$$
\text { Formula: } \mathrm{I}_{\mathrm{s}}=\mathrm{Sprawl}_{\mathrm{C}} \mathrm{C}_{\mathrm{s}}
$$

where Sprawl is the urban dispersion indicator and $\mathrm{C}_{\mathrm{s}}$ the area submitted to land consumption.

This indicator provides information on the relevance of new urban cores located in non-urbanized districts for the total growth of man-made development.

\subsection{Third group of indicators: land consumption impact on the environment}

The indicators included in the second group may well provide their users with an appropriate answer to a number of issues such as the actual relevance of land consumption, the overall area subject to it, the kind of soils most likely to disappear and the debate on the need for either intensifying or reducing human activities However, they do not supply qualitative assessments of land consumption that may link urban transformation with ecological issues and the structure of landscape.

That is why the third group of indicators concentrates on types of urban development and the fragmentation of the land that is derived from the former. This is certainly a more specific feature of territorial planning, but 'breaking up' spatial continuities does have a negative impact on ecosystems' potentialities - e.g. ecological colour, biodiversity reservoirs, ecological continuities, etc. - and natural landscapes.

The fragmentation of space due to increasing urbanization as well as to the construction of more infrastructures and the superimposition of a system of land division jeopardizes the ecosystematic features of the areas under risk - e.g. land, which is of special relevance. Knowing the degree of fragmentation in a given area helps with understanding a series of critical issues that are related to structural modifications in basic features of land use. Similarly, knowing the effects of those modifications should help legislators and decision makers with planning integral policies for the implementation of restorative and preservation actions aimed at maintaining biodiversity.

These are the indicators included in the third group:

Indicator 11: urban fragmentation indicator (UFI).

Calculation method: fragmentation due to an increase in built-up areas. This indicator assesses land fragmentation within urbanized areas which may create barriers; the higher the percentages the index yields, the more important the fragmentation.

$$
\text { Formula: } U F I=\sum L_{i} \times \sqrt{\sum \frac{S u_{i}}{S_{t r}}}
$$

where $\mathrm{L}$ is the urban boundaries maximum dimension $(\mathrm{m}), \mathrm{Su}_{\mathrm{i}}$ the urbanized area $\left(\mathrm{m}^{2}\right)$ and $\mathrm{S}_{\mathrm{tr}}$ the study area $\left(\mathrm{m}^{2}\right)$. 


\section{Indicator 12: infrastructural fragmentation indicator.}

Calculation method: assessing land fragmentation as linked to urban infrastructure - e.g. high tension lines, highways and railway lines, etc.; the higher the percentages the index yields, the more important the fragmentation.

$$
\text { Formula: } I F I=\frac{L_{i}}{S_{t r}}
$$

where $L_{i}$ is the length of infrastructures minus tunnels and ducts $(m)$ and $S_{t r}$ the study area $\left(\mathrm{m}^{2}\right)$.

\section{Indicator 13: density indicator.}

Calculation method: a relationship between the perimeter of a given urban district and an ideal circle whose area is equal to that of the said urban district. The ideal coefficient used is close to 1. (N.B: Urban areas are understood here as both built-up and buildable areas so described in legislation that is applicable for the study area - such as Spanish municipal councils' Planes Generales de Ordenación Urbana, Spanish for 'General Regulations for Urban Planning Management')

$$
\text { Formula: } I L=2 \times \frac{\sqrt{\pi \cdot a_{f}}}{P}
$$

$P$ is the study perimeter.

This indicator provides information on the degree of fragmentation reached in the study area as due to both urban and infrastructural fragmentation. It likewise supplies a density coefficient.

\section{LAND MANAGEMENT INSTRUMENTS: OPERATIONAL TOOLS}

In recent years, a series of initiatives and actions aimed at reducing the impact of human activities on land and natural areas were undertaken in all of the countries which took part in the OSDDT project; therefore, one of the project's aims was both to identify and analyse all of those actions and initiatives as well as the related public policies. The identification and analysis process was carried out by one of the project's partners and showed that public initiatives and the experience gained from them had effectively moved the partners in the direction of sustainable land management and protection of peripheral-urban land - severely damaged by urban sprawl over the last few decades [7].

Actions were carried out both by local and regional authorities and they reflected progressive awareness of the problems and challenges posed by land sealing and consumption. The identified operational tools - both the regulatory-oriented ones and those with a more direct intent - did cover a wide range of intervention fields that can be classified into five categories referring either to the main intervention mode or to the procedure employed (Fig. 6).

The same operational tools may be used for different types of interventions; therefore, tools may be included in different categories depending on the criteria used for classification, as shown in Fig. 7:

Assessing the effectiveness of operational tools is a difficult task, but capitalizing on the OSDDT project partners' experiences may provide valuable instruments for reflection as well as pave the way for identifying new solutions and levers for change in the fight against land consumption.

\subsection{Knowledge-gathering tools: the need for in-depth knowledge of land's ecosystem functions}

From a methodological standpoint, indicators focus on urban areas expansion and the extent thereof, while knowledge-gathering tools may provide experts and decision makers with the necessary information for eventually changing their points of view - if required - on the land consumption-related issues they may face. 

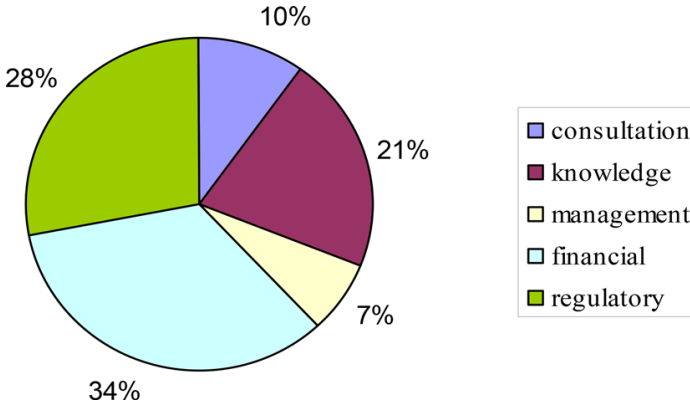

Figure 6: Percentages for tool categories in the OSDDT project.

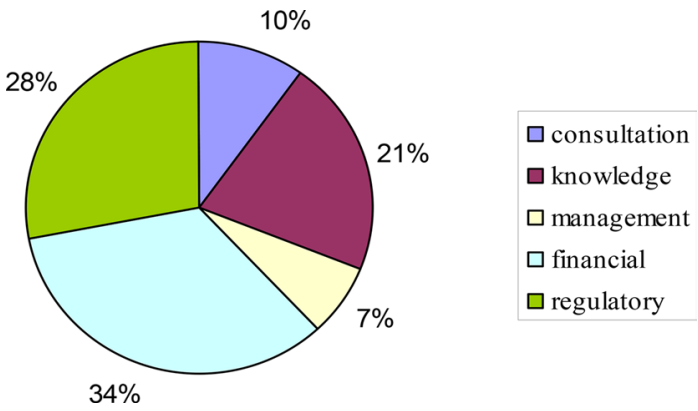

Figure 7: Percentage for tools according to research area.

Knowledge-gathering tools are built on the assumption that a thorough diagnosis of urbanization processes - concerning inputs, landscapes as well as agricultural and natural areas - is required before the said processes are even started. Decisions on urbanization issues specifically require a reliance on a previous assessment of ecosystem functions in the areas involved, so that their actual value for the community can be reliably assessed and ascertained.

Diagnostic processes require that multidisciplinary teams - made out of experts reporting to local and regional governments rather than state-level authorities, designers, academics and researchers - be mobilized. These teams should be monitored by urban planners, agricultural engineers, naturalists, landscapers and even lay citizens.

Knowledge-gathering tools used by the OSDDT project partners considerably differ from each other. For instance, Malta's CORINE Land Cover provides geographic data while accommodating territorial differences and capitalizing on earlier European programmes - e.g. Natura 2000, agrienvironmental measures, etc - for its rural development plan..

As for the French Department of L'Herault, climate change issues have been integrated into the regional government's policies, thus affording the means for the gathering of accurate knowledge on the Department's most fertile soils as well as opportunities for agricultural diversification. Accurate climate and soil data that may be of an interest for a wide range of agents - farmers, planners and elected officials - have been so gathered.

More comprehensive efforts have been carried out at the Italian province of Terni for stimulating collaboration between all the different agents involved as well as a proactive approach to land use issues within local-level development projects. An indicator based on the concept of landscape unit 


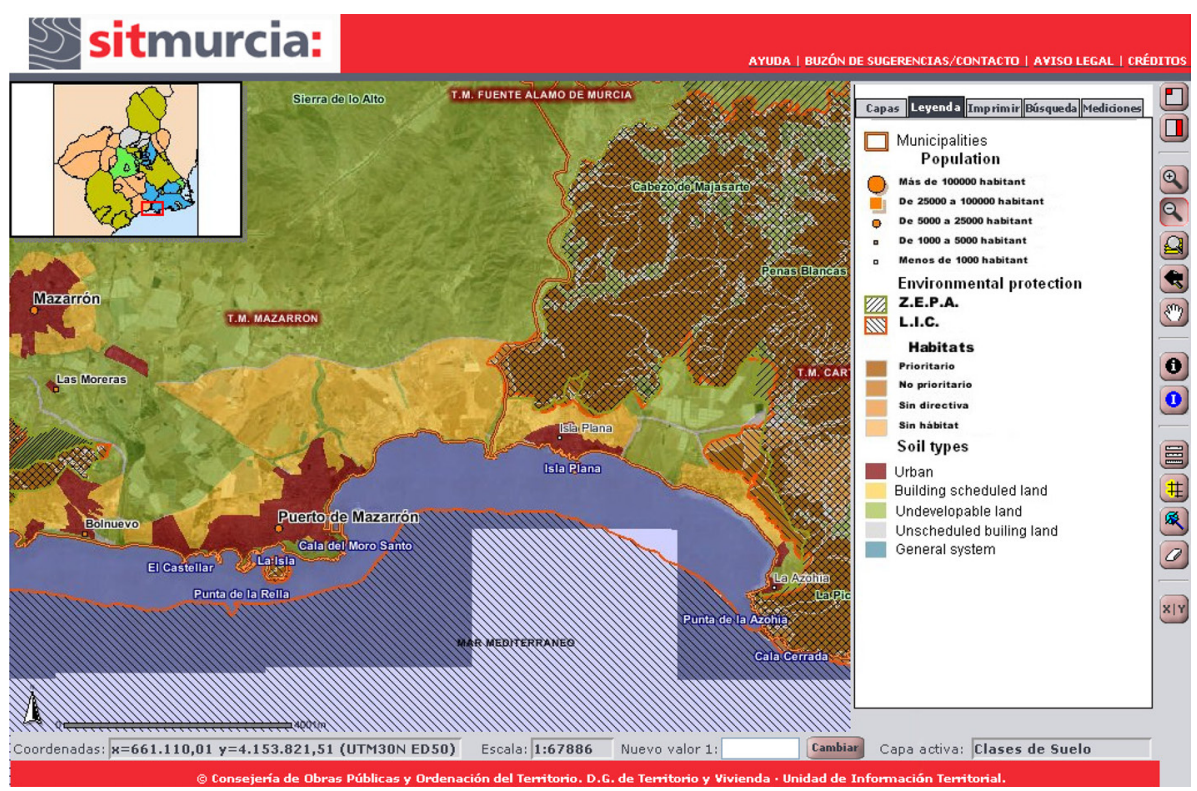

Figure 8: A screen capture from the SitMurcia GIS application, developed at the Spanish Region of Murcia. Source: [8].

has been created for the preservation of landscapes and their biodiversity. Similarly, the diagnostic tools thus developed have become an aid for designing and managing preservation actions. These tools allow for contrast fragmentation between different areas and the preservation of their ecological continuities. Finally, it has to be mentioned that the Spanish Region of Murcia has developed the SitMurcia GIS application (Fig. 8) much along the lines of the tools developed in Terni.

3.2 Regulatory tools: the need for standards at an inter-municipal level that are supported by relevant European directives

An analysis of regulatory tools shows that the OSDDT project partners have their own nationallevel legislation and standards for land planning. Legislative frameworks for land management are important, although it has to be stated that land consumption was not generally taken into account before 2001.

Legislation is anyway not homogeneous and varies from one country to another. Its effectiveness is therefore difficult to establish and may even be challenged by a quantitative assessment of land consumption. The reasons for this are diverse:

1. Different legislation may produce different effects as they do not feature the same requirements. Therefore, legal constraints on land use may be more or less rigid, which raises issues of hierarchy, compatibility and compliance.

2. Legislation is likewise designed for territories that are not homogeneous in size; thus, constraints on land consumption must be imposed that are more wide-ranging in scope.

3. Legislation is enforced by elected officials who may condition land preservation priorities and actions in a given area through different planning instruments. For example, the Spanish Region of Murcia has six different land management plans that cover $60 \%$ of the region's land but do not feature homogeneous specifications (Fig. 9). 

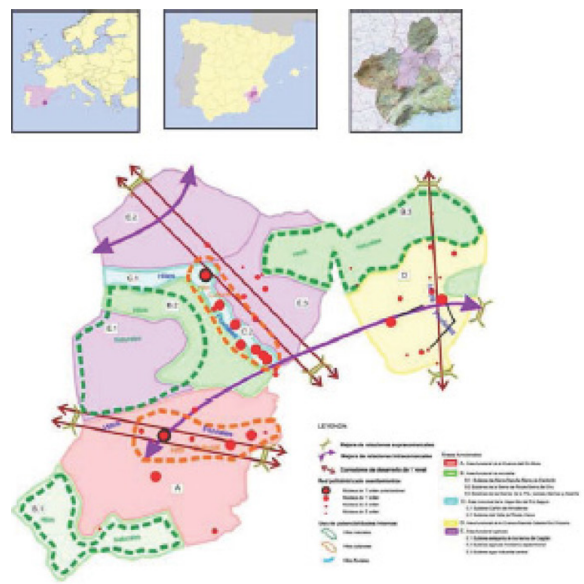

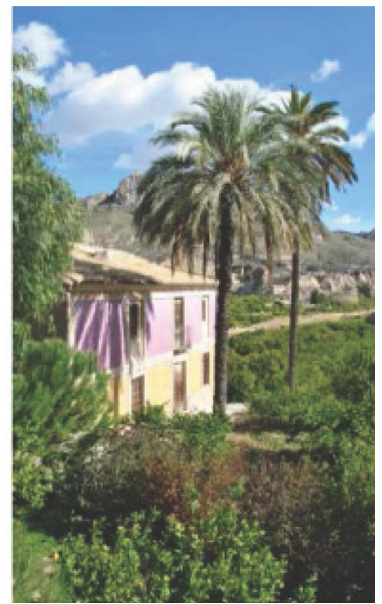

Figure 9: Excerpt from the management plan for the Mula river and the Vega Alta areas in SouthEastern Murcia. Source: [9].

4. Finally, legislation and the regulations and procedures that it establishes are at different stages of development. Some of those regulation and procedures are barely past the diagnostic stage, while others are fully approved and available for independent review.

When facing so relevant an issue as land consumption, legislation had to be complemented by a strengthening of supra-municipal standards already included in the existing planning instruments either at regional, provincial or departmental levels. The use of these regulatory tools is, however, conditioned by the political will of local decision makers, and it is still too early to assess its effectiveness. That being the case, it has to be stated that the monitoring of land consumption is possible wherever homogeneous, national-level quantitative indicators exist, and land consumption has been surveyed - especially when the said surveys have not been carried out as required by then-existing regulatory frameworks.

The analysis of regulatory tools highlights a decisive lack - that of a homogenous European directive that effectively reduces land consumption and provides ways for acting more effectively against it at the inter-municipal or supra-municipal levels.

\subsection{Financial tools: the need for new models of intervention in land}

As the experience gained from the OSDDT project shows, it is not enough for the fighting against urban sprawl to be integrated into legislation. New models for intervention that take into account the economic evolution of land and its impact on landscape are needed at the local level (Fig. 10).

The analysis conducted by the OSDDT project partners shows the need for the public to be involved with the initiatives against land consumption as well as that for ad hoc, long-term public funding. Many of those initiatives have a pedagogical value and seek to show that both approaches to land use that are less intensive in nature and the improvement of existing natural resources are feasible options [11]. The pilot projects carried out - in such fields as green space, landscaping, ecological continuity and suburban agricultural areas - have the promotion of land's systemic ecofunctions as one of their goals. 


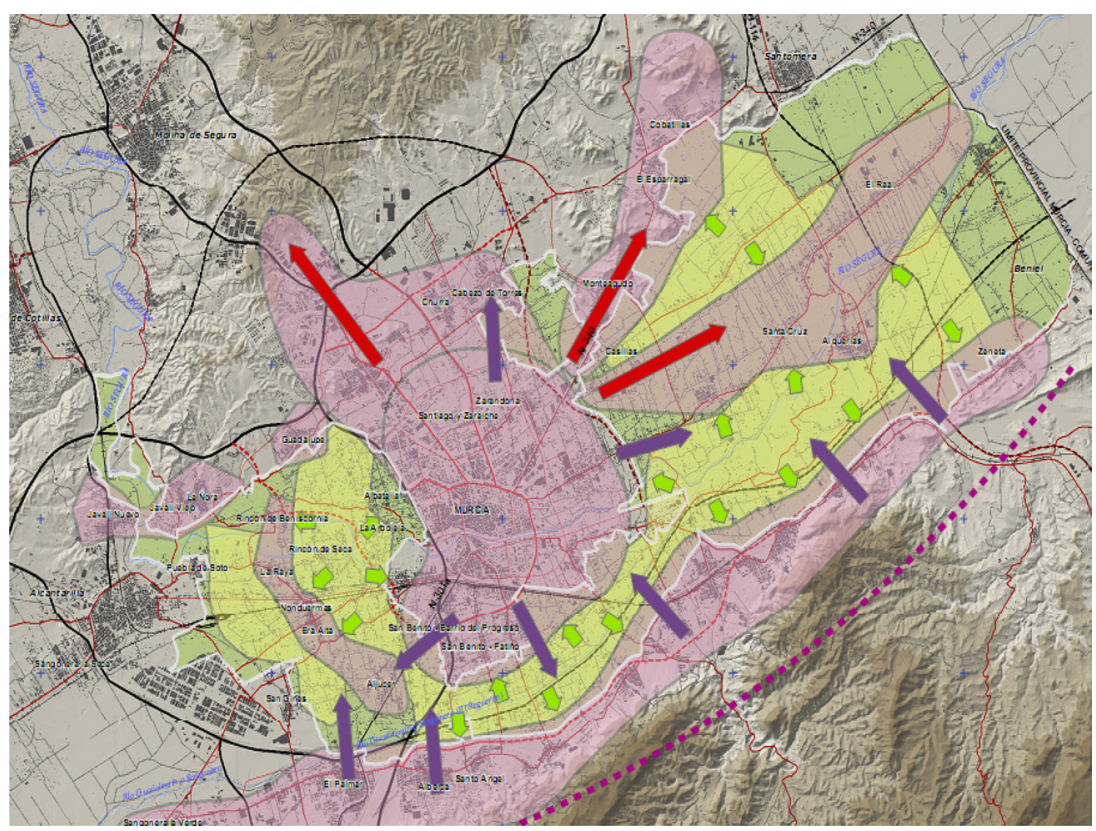

Figure 10: Economic trends in land use in relation to landscape in the city of Murcia. Source: [10].

These are initiatives that can be actually implemented, as shown by the experiences carried out within the OSDDT project. First, methodologies for the design, implementation and development of local-level projects such as eco-districts - for areas with denser habitats although not yet benefitting from proposals for rural development - were exchanged. The OSDDT project likewise tackled the valorization of landscapes and highly valuable sites from a heritage point of view - including initiatives such as landscape planning, protection of natural areas under threat and landscape integration of buildings for agricultural purposes. Major actions were also carried out for the preservation of biodiversity through sustainability of ecological continuities - e.g. creation of green belts, coastal strip preservation, etc. Finally, programmes for the development and preservation of agricultural areas subject to urbanizing pressure - promoting denser urbanization and a spirit of social and functional diversity - were devised as well.

\subsection{Consultation tools: the need for raising awareness among the public and elected officials}

Awareness of the need for preserving land and the risk posed by overconsumption should not be a purely technical matter: the public should be provided with information on those issues, as it is clear that the land consumption issue has implications for citizenship, civic education and participatory democracy.

Public dialogue and participatory democracy are procedures that are developed over time as both land use and society demands evolve differently. For the OSDDT project, this meant that tools for consultation could not be homogeneous as cultural, historical, political and administrative factors in the countries involved were not homogeneous either.

In this state of things, it is important to capitalize on the methodologies used and the know-how gained through consultation, as well as to share both the former and the latter. However, the OSDDT 

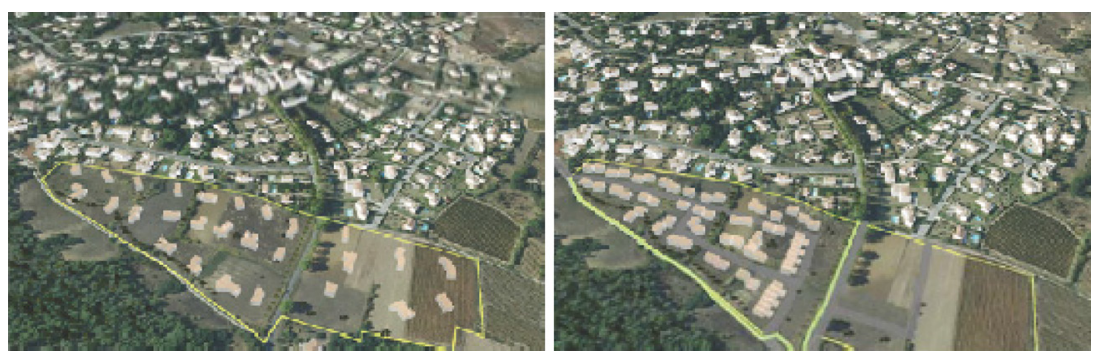

Figure 11: Visualization of 3D projects used as a consultation tool. Source: [12].

project's experience shows that there is still a lack of consultation tools. Methodological repositories could be helpful too, as well as feedback on the use of computer tools for simulation and visualization of the impact of planned interventions - as a means to support the consultation process. These tools should be understandable for the public in order to be effective (Fig. 11).

\subsection{Tools for project management: the need for promoting ambitious development plans}

Some of the identified tools were used for monitoring of current infrastructure - e.g. roads, motorways and intermodal trade centres. This highlighted the importance of transport in its relation to space and land development..

The use of the said tools also reflected the complex evolution of behaviours and expectations. A good example of this is the evolution of transportation systems, which are currently starting to favour intermodal solutions to the detriment of monofunctional infrastructures exclusively based on road transportation. For this purpose, the Spanish Region of Murcia's experts have developed the IDERM GIS application - Infraestructura de Datos Espaciales de Referencia de La Región de Murcia, Spanish for 'The Region of Murcia Reference Spatial Data Infrastructure [12] (Fig. 12).

A number of large-scale projects have also aimed at countering the impact of infrastructure on land with different actions - improvement of urban areas, integration of natural ones, etc. [13]. There is a public demand for that sort of actions, which is connected with issues of sustainable development, global warming, fossil fuels' shortage and transportation needs. All of these pave the way for the design of new proximity-based approaches to transportation as required by new models of sustainable development for cities (Fig. 13).

\section{RESULTS AND CONCLUSIONS}

A number of results yielded by the use of the aforesaid indicators and tools were presented at the 8th International Conference on Urban Regeneration and Sustainability - Sustainable City 2013 - held in Malaysia by means of the retrospective analysis system described in [4]. Land use assessment models have become increasingly sophisticated over the years because of the growing number of variables to be assessed and the complex problems posed by administrative matters; therefore, it is important to implement new analysis and diagnostic methodologies for improving governance in urban planning and land management.

From a theoretical point of view, this paper has discussed the main criteria used for establishing a model of retrospective analysis of land use based on the results yielded by the OSDDT project. In order to formulate an accurate diagnosis of land use, it is important to establish at least three groups of indicators covering the land consumption rate on the study areas as well as urban sprawl-related issues and the impact of land consumption on the environment. As far as the said indicators are con- 


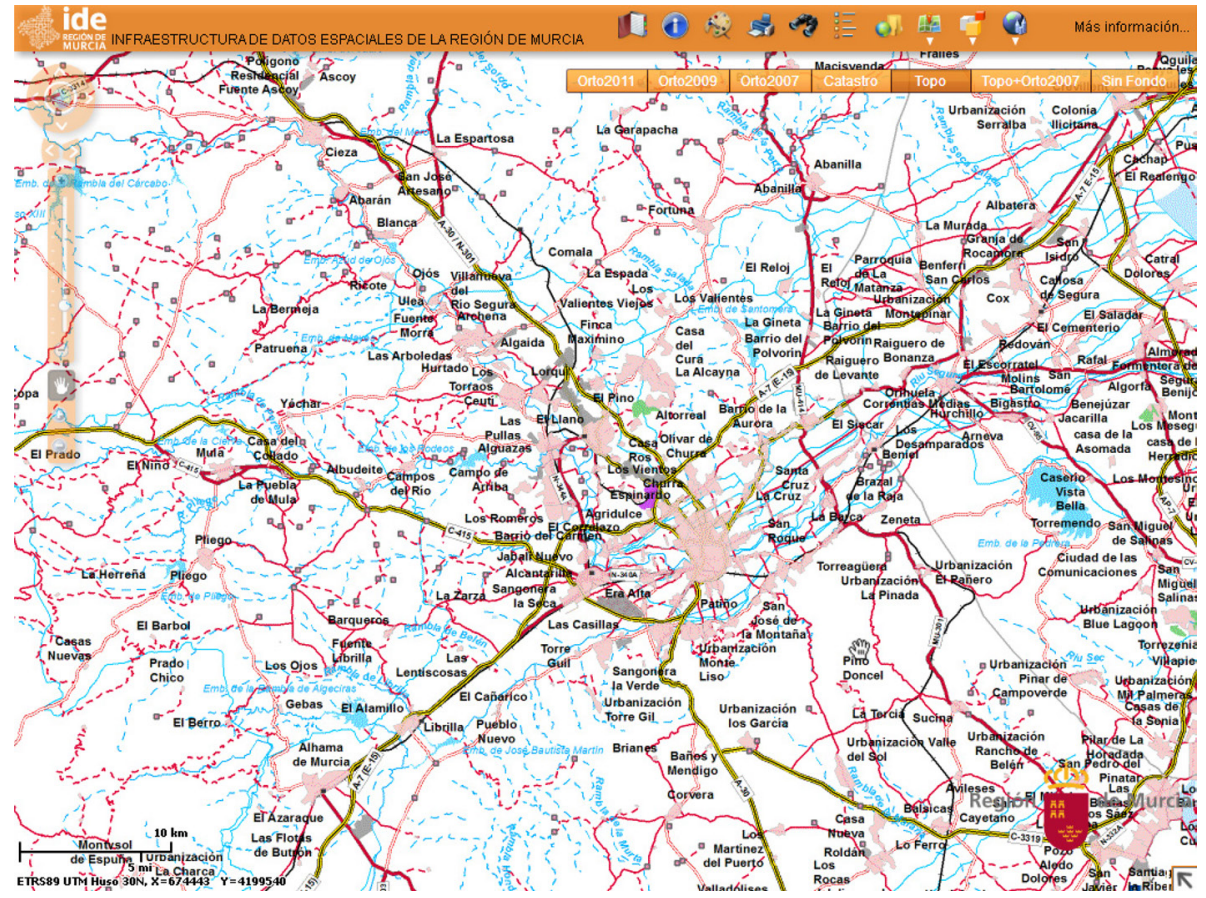

Figure 12: IDERM tool of the Region of Murcia. Source: [12].

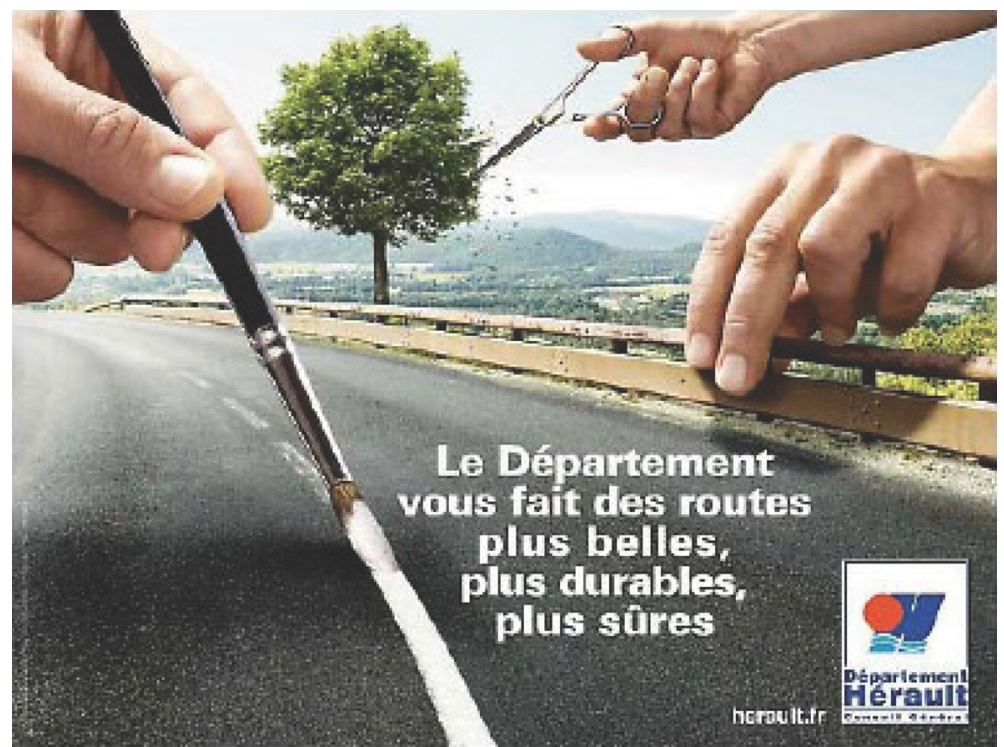

Figure 13: 'The Department is building roads for you that are more beautiful, sustainable and safe'. Example of sustainable management tools in the French Department of Hérault. Source: [13]. 
cerned, it is possible to infer that there is a possibility for them to be used by experts working for European government authorities at the local level, provided they are equipped with Geographic Information System applications and they have stable nomenclature information on land use as well as accurate tools. In this sense, satellite imagery may provide excellent information as long as images are high-quality ones.

In terms of operational tools, the OSDDT methods highlight a lack of political will in European countries: the approval of a relevant European directive could limit land use and offer new possibilities for the regulation of urban sprawl. As for this, the need to move towards using new tools that are able to integrate knowledge-gathering, management, financial, regulatory and consultation capabilities for improving political decision-making remains a decisive factor in the fight against land consumption.

\section{REFERENCES}

[1] Otremed, OSDDT and Pays Med Urban: European Med program 2007-2013. CTE 0, Axes 2 \& 4. 2nd call - classical projects, 2009. www.sdimed.eu, www.osddt.eu and www.paysmed.net.

[2] Naturba: SUDOE Interreg IV program. Code SOE1/P4/F201.

[3] Miralles i Garcia, J.L., Díaz Aguirre, S. \& Altur Grau, V.J., Environmental impact on the Mediterranean Spanish coast produced by the latest process of urban development. WIT Transactions on Ecology and The Environment, 155, pp. 379-389, 2012. doi: http://dx.doi.org/10.2495/ $\underline{\mathrm{sc} 120321}$

[4] Garcia-Ayllon, S., Retrospective analysis of urban development in the Spanish Mediterranean coast. WIT Transactions on Ecology and the Environment, 179, pp. 291-302, 2013. doi: http:// dx.doi.org/10.2495/sc130251

[5] Directive 2007/2/EC of the European Parliament and of the Council of 14 March 2007 establishing an Infrastructure for Spatial Information in the European Community (INSPIRE).

[6] Piano Territoriale di Coordinamento della Provincia di Torino. http://www.sistemapiemonte. it/territorio/ptcp/.

[7] Miralles i Garcia, J.L., Real estate crisis and sustainability in Spain. Proceedings of the Sustainable Development and Planning V, eds. C.A. Brebbia \& E. Beriatos, WIT Press: Southampton, pp. 123-133, 2011. doi: http://dx.doi.org/10.2495/sdp110111

[8] Sitmurcia - Sistema de Información Territorial de la Región de Murcia. Consejería de Obras Públicas y Ordenación del Territorio de la Region de Murcia. www.sitmurcia.es.

[9] Directrices y Plan de Ordenación Territorial de la Comarca del Río Mula, Vega Alta y Oriental. Comunidad Autonoma de la Región de Murcia.http://www.carm.es/web/integra.servlets. Blob?archivo=detor.pdf $\&$ tabla $=$ archivos $\&$ campoclave $=$ idarchivo $\&$ valorclave $=61468 \&$ campo imagen $=$ archivo\&idtipo $=60 \&$ rastro $=c 217 \$ \mathrm{~m} 2594,24302$.

[10] Decreto no. 102/2006, de 8 de junio, por el que se aprueban las 'Directrices y Plan de Ordenación Territorial del Suelo Industrial de la Región de Murcia'. http://www.sitmurcia.es/ gestionot/dirind.

[11] Miralles, J.L. \& García-Ayllón, S., The economic sustainability in urban planning: case La Manga. WIT Transactions on Ecology and the Environment, 173, pp. 279-290, 2013. doi: http:// dx.doi.org/10.2495/sdp130231

[12] Región de Murcia. Infraestructura de Datos Espaciales de Referencia de la Región de Murcia. www.cartomur.imida.es/.

[13] Département de 1’Hérault. Programme d'intégration d'infrastructures. http://www.herault.fr/ routes-transports. 